\title{
Work Stress and Self-Reported Health Problems in Female Ready Made Garment Workers
}

\author{
Article by Suraiya Ahmed ${ }^{1}$, Manzurul Haque Khan ${ }^{2}$ and Irin Hossain ${ }^{3}$ \\ ${ }^{1}$ Chattagram International Dental College \\ ${ }^{2,3}$ National Institute of Preventive and Social Medicine, Mohakhali, Dhaka \\ E-mail: irin.hossain@gmail.com ${ }^{3}$
}

\begin{abstract}
A cross sectional descriptive study was conducted to assess work stress and self-reported health problems in female ready-made garment workers. This cross sectional study was carried out on a sample of 310 female workers selected purposively from a ready-made garment factory located in Savar, Dhaka. Work stress was estimated by using an ERIs questionnaire; while self-reported health problems, workrelated information and socio-demographic information were obtained using a semi-structured questionnaire by face to face interview. The study was conducted for a period of one year extending from January 2014 to December 2014 in a Ready-made Garment factory of Bangladesh located in Hemayetpur bus stand, Savar, Dhaka. The mean age of the respondents was $27.26 \pm 5.93$ years and they were mostly married (71.3\%). Most of them (55.5\%) had primary education and another $20.0 \%$ never went to school. The mean monthly and per capita family incomes of the respondents were Tk7573.55 961.06 and Tk3831.50 1892.94 respectively. Among the respondents, 59.7\% worked in the sewing section, followed by $14.8 \%$ in the finishing section. Their mean duration of employment and total working hours per week was $36.68 \pm 17.92$ months and 58.35 \pm 3.08 hours respectively. About one fifth (22.9\%) of the study participants were found to have high stress. Almost 53.2\% respondents were found to have been suffering from headache for last 2 months. Back pain and chronic cough was significantly associated with age and total work time per week ( $p<0.05)$. Shoulder pain, stomach problem, pain/burning of eye, fatigue and general weakness was significantly associated with age ( $p<0.05)$. Painful/burning micturation was also significantly associated with age and total work time per week $(p<0.05)$. High stress was not uncommon among female ready-made garment workers. Self-reported health problems were found to be associated with socio-demographic and work related factors. Programs should be taken to reduce working environment stressors, to enhance wellbeing conditions. A further analysis report using delegate sample from ready-made garment sector needs to be undertaken to obtain generalizable findings.
\end{abstract}

Keywords: Work stress, self-reported health problem, Ready Made Garment Workers.

\section{Introduction}

The Ready-made Garment (RMG) industry in Bangladesh is the major foreign currency earning sector with the highest employment rate. Bangladesh exported garments worth the equivalent of US \$10.7 billion in 2008, which was about 3.87 per cent of the global total value (US \$276 billion) of garment exports [1]. The Ready-made Garment (RMG) sector draws global attention for its quality production and huge employment women workers. From decades after decades we have seen the reliance on Garment industry developing in Bangladesh. In 1983, there were around 50 piece of garment factories in the nation. In 2004, this number had jumped to 4,000. In 2009, there are about 4500 garment factories in Bangladesh. Currently, this sector employs approximately 2.2 million workers, of whom almost $80 \%$ are women [2]. Factory sizes vary between around 200 and 1,200 workers, with an average of about 550-600 workers [3]. The media and successive Bangladesh governments portray the country's garment workers as the "pride" of the nation and female workers as the "golden girls", an image that also serves as an indicator of Bangladeshi women's emancipation in popular national and global discourses [4]. 
The working conditions in RMG factories have been progressively highlighted by the Western media as being described by low wages, openess to violence and a high work load. It is well known that physically and psychologically taxing working conditions are important determinants of employees' health [5]. About one out of four European workers reports having to work at very high speed all or almost all the time, and in the USA one out of four workers complains about being frequently burned out or stressed by his or her job [4]. Most of the health problems that the garment workers suffered arose from the occupational hazards including long working hours, absence of leave facilities, congested and overcrowded working conditions, absence of health facilities and safety measures, absence of staff amenities, lack of safe drinking water etc., [6].

Raymond explained "Stress is the reaction people have to excessive pressures or other types of demand placed upon them. It arises when they worry that they cannot cope" [7]. Holmes and Rahe (1967) found that the more significant changes person had in his or her life, the greater the chance that he or she would contract some physical or psychological illness. Estimates of the total cost of stress and stress-related illness vary enormously, self- reported work-related stress account for an estimated 12.8 million reported lost working days per year in Britain [7]. In 2004, HSE Annual Report revealed the astounding figure of 13.4 million days lost due to stress. About half of the workers reported an unambiguously positive impact of their job on their health (considering effects on both mental and physical health). A national sample of 2,048 workers was asked to rate the impact of their job on their physical and mental health. Workers who had higher levels of perceived constraints and neuroticism, worked nights or overtime, or reported serious ongoing stress at work or higher job pressure reported more negative effects. Both people working the night shift and those working more than full time were about one quarter more likely to report unambiguously negative effects of work on health.

Work and health are intimately connected, yet the complex association is not well understood, because features of both the employee and the employment context influence worker well-being [8]. The negative implications of work stress are recognized as a challenge to both employers and workers, with women, youth, shift, part-time, and nonwhite collar workers being more likely to have high-strain jobs. Those with such jobs perceived their work to be physically demanding and less satisfying. Low personal incomes and low levels of education were also associated with higher stress [9]. Work-related stress is a growing concern for employees and employers in the European Union. Work-related stress has been associated with a number of other ill-health outcomes, such as cardiovascular disease, musculoskeletal disorders, particularly back problems and neck-shoulder-arm-wrist-hand problems, as well as absence from work. Work and family are the two domains from which most adults derive satisfaction in life; equally they are the common sources of stressful experiences. The implications of work-related stress include the effects on worker satisfaction and productivity, their mental and physical health, absenteeism and its economic cost, the wider impact on family function and finally, the potential for employer liability. Occupational stress is of increasing importance due to continuing structural changes in the workplace, with both increasing demands and job insecurity imposed on employees [10].

Work-related stress is one of the leading causes of workers' ill health in developed countries, where it has considerable effects on sickness absence and disability. Epidemiological investigations document significant associations of stressful work with coronary heart disease, depression, musculoskeletal disorders and other stress related health problems. Women represent 85 percent of the total 2.4 million employees in the Ready- Made Garment (RMG) industry. Employment in the garment industry has increased the average age of marriage and improved women's financial situation, but many difficulties remain, including significant challenges to women's health. Women in Bangladesh are more malnourished than men at every stage of life but this phenomenon is more visible in the case of adolescent girls and pregnant mothers. The WHO calls anemia a 'severe' public health problem in Bangladesh. There is less rights including maternity leave, factory child-care facilities, nursing breaks, and hygienic toilet facilities. The present study attempted to identify common health problems (selfreported) and level of work stress among female ready-made garment workers. 


\section{Background}

This study took a unique approach to studying the work-health relationship by examining the correlates of workers ratings of how their job affects their health. About half of the workers reported an unambiguously positive impact of their job on their health (considering effects on both mental and physical health). A national sample of 2,048 workers was asked to rate the impact of their job on their physical and mental health. Ordered logistic regression analyses based on social ecology theory showed that the workers' responses were significantly correlated with objective and subjective features of their jobs, in addition to personality characteristics. Workers who had higher levels of perceived constraints and neuroticism, worked nights or overtime, or reported serious ongoing stress at work or higher job pressure reported more negative effects. Respondents, who had a higher level of extraversion, were selfemployed or worked part time or reported greater decision latitude or use of skills on the job reported more positive effects. Both people working the night shift and those working more than full time were about one quarter more likely to report unambiguously negative effects of work on health. Work and health are intimately connected, yet the complex association is not well understood, because features of both the employee and the employment context influence worker well-being [8].

Drawing on insights from previous ethnographic research, researcher conducted a cross-sectional epidemiological study among 332 RMG workers in Dhaka, Bangladesh. This study identified three key components of the work stress in the RMG factory setting; these were work-related demands, interpersonal resources, and work-related values. Study sample comprising mainly female young workers with low educational back- grounds. The daily income was 230 Bangladeshi Taka (BDT) (\$2.7) or less per day for $89 \%$ of the employees. The mean weekly overtime equaled $7.5 \mathrm{~h}$ (SD 3.8). Forty-one percent of the respondents reported poor health. Jaundice, breathing problems and stomach problems were reported by $6.0 \%, 13.0 \%$, and $16.3 \%$ of the participants, respectively. Approximately one quarter of the study participants indicated back pain, sleeplessness, and muscle cramps during the last two months. Overall, high work-related demands showed positive associations with poor SRH and with the individual physical symptoms. For instance, an increase of the demand score by one SD was associated with a significantly $59 \%$ increased odds of poor SRH. Work- related demands and interpersonal resources were found to be associated with RMG workers health while work-related values seemed to be of less relevance in this respect [17].

\section{Methods}

\section{Study design and sample}

The study was conducted for a period of one year extending from January 2014 to December 2014 in a Ready-made Garment factory of Bangladesh located in Hemayetpur bus stand, Savar, Dhaka. . There are five working section in the factory. These are cutting, sewing, quality control, operator and finishing. All the female workers of Meridian Fashion Wear Ltd, Hemayetpur bus stand, Savar, Dhaka, worked at different section of the factory are the study population. Female workers who are working at least one year in the selected garment were eligible for the study. Female workers age less than 18 years were excluded from the study. The ultimate sample size for the study was 310 which were selected by purposive sampling. A structured questionnaire was designed to collect information on sociodemographic variables (e.g. age, marital status, religion, educational qualification, monthly income, family income, family member, earning family members) and related information about work place (e.g. duration of employment, working section, daily working hours, weekly overtime hours). Effort-Reward Imbalance (ERI) questionnaire was used for measuring work stress. The original ERI was developed by Johannes Siegrist and Diego Montano in 2013. There are two versions of ERI questionnaires (ERI-Q): the long version (ERI-L) and the short version (ERI-S).For this study researcher used the short version (E RIS) questionnaires, which consists of 10 effort and reward item [11]. In ERI first 3 items are for effort and the remaining 7 items for reward. The rating procedure consists of a verbal rating scale of four ordered categories, which was used by the researcher to construct the corresponding scores. The response format 
DOI: $10.21522 / \mathrm{TIJPH} .2013 .05 .04$. Art056

ISSN: $2520-3134$

and numerical values are following: (1) strongly disagree, (2) disagree, (3) agree, (4) strongly agree. The scale purpose is to measure the stress which workers perceive from various constituents and conditions of their job. In this study, those items are related to almost all relevant components of job life which cause stress in some way or other. The reliability of the original scale was measured through EMA (Ecological momentary Assessment) technique and all Cronbach's alpha coefficients are equal to or higher than 0.80 indicating a satisfying internal consistency [11]. The ERI-S questionnaire was translated to Bengali and that was back translated with assist of a people.

Inventory for self-reported health problems consists of 12 questions concerning common health problems regarding garment workers which subjects answer yes or no. The health problems are back pain, neck pain, shoulder pain, stomach problem, breathing problem, headache, chronic cough, pain/burning of eyes, sleeplessness, painful/burning micturation, fatigue and general weakness $[4,5]$. Ethical clearance was taken from the Ethical committee. Before the onset of the study, pretesting was carried out on 10 cases to finalize the procedure and to evaluate the effectiveness of the research instruments. Modifications were made as necessary and the research instruments were finalized. The researcher was collecting the required data through interview administered questionnaire, after having their informed consent. The workers were assured about the confidentiality of the information provided by them. The data entered into computer, processed and tabulated to get a master sheet. Then coded data were analyzed by using Statistical Package for Social Science called SPSS version 11.5 for windows. Data were checked, clean and edited properly. After that data were coded and categorized. The Effort-Reward ratio was computed for each respondent according to the formula: $e /\left(\mathrm{r}^{*} \mathrm{c}\right)$ where e is the sum score of the effort scale, $\mathrm{r}$ is the sum score of the reward scale and $\mathrm{c}$ defines a correction factor. Here, $\mathrm{c}=$ number of reward items/ number of effort items that is $7 / 3$. From effort-reward ratio values $>1$ indicate high stress and $\leq 1$ indicate low stress [13].

The analysis were include description of the study population by their socio-demographic characteristics at first instance using certain descriptive statistics, frequency distribution tables on frequencies, percentages, mean, median \& IQR. In order to find out association between two or more variables Chi-Square test and Fisher's exact test were performed to see the statistical significance. Graphical software was used for creation of charts by using Microsoft Excel.

\section{Analysis}

The focus of this analysis is on the pathways linking work stress and self-reported health problems in female ready-made garment workers. Data processing and analysis was done using SPSS (Statistical Package for Social Sciences) version 22. The test statistics was used to analyze the data is descriptive statistics and inferential statistic according to the demand of the study with $95 \%$ confidence interval. Level of significance was set at 0.05 . Qualitative data were analyzed on the basis of themes.

\section{Result}

\section{Socio-demographic characteristic of the respondents}

This table 1 shows the distribution of the respondents by age which varies between the age of 18 to 40 years and their mean age was $27.26(\mathrm{SD} \pm 5.93)$ years. Most of the respondents $(47.4 \%)$ were between 21 29 years, $36.5 \%$ were more than or equal 30 years and the remaining $16.1 \%$ were equal or less than 20 years. Among the respondents $71.3 \%$ (221) were married, $23.5 \%$ (73) were unmarried and the remaining $5.2 \%$ (16) were divorced/ widowed. Among them 88.4\% (274) were Muslim, 9\% (28) were Hindus, $1.3 \%$ (4) were Buddhist and the remaining 1.3\% (4) of them were Christian. This table 1 shows distribution of the respondents by their educational status. Among them $20.0 \%$ of the respondents never went to school, majority $55.5 \%$ went for Primary education and the remaining $24.5 \%$ went for Secondary/Higher education. Most (51.3\%) of the respondents monthly income were more than Tk 7,500 and rest of them $48.7 \%$ had a monthly income of $\mathrm{Tk} 7,500$ or less. 
Table 1. Socio-demographic characteristics of the respondents

\begin{tabular}{|l|l|l|}
\hline Characteristics & Frequency & Percent \% n= 310 \\
\hline Age (Years) & 50 & 16.1 \\
\hline$\leq 20$ & 147 & 47.4 \\
\hline $21-29$ & 113 & 36.5 \\
\hline$\geq 30$ & 62 & 20.0 \\
\hline Level of Education & 172 & 55.5 \\
\hline Never went to school & 76 & 24.5 \\
\hline Primary & \multicolumn{2}{|l|}{} \\
\hline Secondary/Higher & 151 & 48.7 \\
\hline Monthly Income & 159 & 51.3 \\
\hline$\leq 7500.00$ &
\end{tabular}

\section{Distribution of the respondents by working section}

This table 2 shows distribution of the respondents by working section. Among the respondents $59.7 \%$ of the respondents belong to sewing section, $6.1 \%$ in cutting section, $12.3 \%$ of the respondents in quality control section, $7.1 \%$ of the respondents in operator section and $14.8 \%$ of the respondents belong to finishing section.

Table 2. Distribution of the respondents by working section

\begin{tabular}{|l|l|l|}
\hline Working section & Frequency & Percent $(\%) \mathbf{n}=\mathbf{3 1 0}$ \\
\hline Cutting & 19 & 6.1 \\
\hline Sewing & 185 & 59.7 \\
\hline Quality control & 38 & 12.3 \\
\hline Operator & 22 & 7.1 \\
\hline Finishing & 46 & 14.8 \\
\hline
\end{tabular}

\section{Distribution of the respondents by total working hours per week}

Among 310 of the respondents, $85.8 \%$ of them were engaged in work for above 54 hours per week, $9.0 \%$ of them were engaged in work for $49-54$ hours per week and the remaining $5.2 \%$ of them were engaged in work for 54 hours or above per week. The mean of the total working hours per week was $58.35( \pm 3.08)$ hours whereas the minimum total working hours per week was 48 hours and maximum was 62 hours.

Table 3. Distribution of the respondents by total working hours per week

\begin{tabular}{|l|l|l|}
\hline Total working hours per week & Frequency & Percent $(\%) \mathbf{n = 3 1 0}$ \\
\hline$\leq 48$ & 16 & 5.2 \\
\hline $49-54$ & 28 & 9.0 \\
\hline$>54$ & 266 & 85.8 \\
\hline
\end{tabular}

\section{Distribution of the respondents by work stress}

Among 310 of the respondents, $77.1 \%$ of them had low stress and the remaining $22.9 \%$ of them had high stress. 
DOI: $10.21522 / \mathrm{TIJPH} .2013 .05 .04$. Art056

ISSN: $2520-3134$

Table 4. Distribution of the respondents by work stress

\begin{tabular}{|l|l|l|}
\hline Work stress & Frequency & Percent $(\%) \mathbf{n = 3 1 0}$ \\
\hline Low stress $(\leq 1)$ & 239 & 77.1 \\
\hline High stress $(>1)$ & 71 & 22.9 \\
\hline
\end{tabular}

\section{Distribution of the respondents been suffering from health problems for last two months}

This table 5 shows distribution of the respondents has been suffering from health problems for last two months. Headache was the most common (53.2\%) health problem among the respondents. Moreover a good number of workers face back pain, fatigue, neck pain, pain/burning of eyes, shoulder pain, stomach problem with the percentage of 42.6, 41.0, 31.9, 30.6, 28.7, 26.8 respectively.

Table 5. Distribution of the respondents been suffering from health problems for last two months: $n=310$

\begin{tabular}{|l|l|l|}
\hline Health problems & Frequency & Percent $(\%)$ \\
\hline Back pain & 132 & 42.6 \\
\hline Neck pain & 99 & 31.9 \\
\hline Shoulder pain & 89 & 28.7 \\
\hline Headache & 165 & 53.2 \\
\hline Breathing problem & 61 & 19.7 \\
\hline Stomach problem & 83 & 26.8 \\
\hline Chronic cough & 24 & 7.7 \\
\hline Pain/Burning of Eyes & 95 & 30.6 \\
\hline Painful/Burning Micturation & 36 & 11.6 \\
\hline Sleeplessness & 61 & 19.7 \\
\hline Fatigue & 127 & 41.0 \\
\hline General weakness & 57 & 18.4 \\
\hline
\end{tabular}

\section{Socio-demographic characteristics and work stress}

This table 6 shows that high stress was found to be most prevalent among 21-29 years age group workers (25.2\%). Among 20 years or below age group workers $18.0 \%$ and among the 30 years or above age group workers $22.1 \%$ had high stress. Furthermore no significant association between work stress and age group was detected $(\chi 2=1.147, \mathrm{df}=2, \mathrm{p}>0.05)$. This table 6 shows that high stress was found to be most prevalent among non-schooling workers (25.8\%). Among the primary $23.3 \%$ and the secondary/higher educational group $19.7 \%$ workers had high stress. High stress was found to be most prevalent among those workers having a monthly income of Tk 7500or less. Furthermore no significant association between work stress and monthly income was detected. $(\chi 2=1.426, \mathrm{df}=1, \mathrm{p}>0.05)$. High stress was most prevalent among those having a family of 4 to 6 person (25.0\%) and lowest (18.6\%) among those having a family of 3 person or less. 
Table 6. Socio-demographic characteristics and work stress $n=310$

\begin{tabular}{|c|c|c|c|c|c|}
\hline \multirow[t]{2}{*}{ Characteristics } & \multicolumn{2}{|c|}{ Work Stress } & \multirow[t]{2}{*}{ Total $(\%)$} & \multirow[t]{2}{*}{$\mathbf{P}$} & \multirow[t]{2}{*}{$\chi^{2}$} \\
\hline & $\begin{array}{l}\text { Low } \\
\text { stress }(\leq 1) \\
\text { n }(\%)\end{array}$ & $\begin{array}{l}\text { High } \\
\text { stress }(>1) \\
\text { n }(\%)\end{array}$ & & & \\
\hline \multicolumn{6}{|l|}{ Age (Years) } \\
\hline$\leq 20$ & $41(82.0)$ & $9(18.0)$ & $50(16.13)$ & \multirow[t]{3}{*}{0.563} & \multirow[t]{3}{*}{1.147} \\
\hline $21-29$ & $110(74.8)$ & $37(25.2)$ & $147(47.42)$ & & \\
\hline$\geq 30$ & $88(77.9)$ & $25(22.1)$ & $113(36.45)$ & & \\
\hline \multicolumn{6}{|l|}{ Education Level } \\
\hline $\begin{array}{l}\text { Never went to } \\
\text { school }\end{array}$ & $46(74.2)$ & $16(25.8)$ & $62(20)$ & \multirow[t]{3}{*}{0.691} & \multirow[t]{3}{*}{0.740} \\
\hline Primary & $132(76.7)$ & $40(23.3)$ & $172(55.48)$ & & \\
\hline Secondary/Higher & $61(80.3)$ & $15(19.7)$ & $76(24.52)$ & & \\
\hline \multicolumn{6}{|c|}{ Monthly Income (Taka) } \\
\hline$\leq 7500.00$ & $112(74.2)$ & $39(25.8)$ & $151(48.71)$ & \multirow[t]{2}{*}{0.232} & \multirow[t]{2}{*}{1.426} \\
\hline$>7500.00$ & $127(79.9)$ & $32(20.1)$ & $159(51.29)$ & & \\
\hline \multicolumn{6}{|l|}{ Family Size } \\
\hline$\leq 3$ & $57(81.4)$ & $13(18.6)$ & $70(22.58)$ & \multirow{3}{*}{0.537} & \multirow{3}{*}{1.244} \\
\hline 4 to 6 & $135(75.0)$ & $45(25.0)$ & $180(58.06)$ & & \\
\hline$\geq 7$ & $47(78.3)$ & $13(21.7)$ & $60(19.35)$ & & \\
\hline
\end{tabular}

Relationship between Work Stress and duration of employment, working section, total work time per week

This table 7 shows that high stress was most prevalent (25.6\%) among those workers who are working for 24 months or less. Furthermore no significant association between work stress and duration of employment was detected $(\chi 2=0.799, \mathrm{df}=3, \mathrm{p}>0.05)$. High stress was most prevalent among those workers who are working at quality control section $(34.2 \%)$ and $32.6 \%$ among those workers who are working at finishing section. High stress was most prevalent (32.1\%) among those workers who are working for 4954 hours per week and $25.0 \%$ among those workers who are working for 48 hours or less. Furthermore no significant association between work stress and total work time per week was detected $(\chi 2=1.575, \mathrm{df}=2, \mathrm{p}$ $>0.05)$.

Table 7. Relationship between work stress and duration of employment, working section, total work time per week $\mathrm{n}=310$

\begin{tabular}{|c|c|c|c|c|c|}
\hline \multirow[t]{2}{*}{ Characteristics } & \multicolumn{2}{|c|}{ Work Stress } & \multirow[t]{2}{*}{ Total $(\%)$} & \multirow[t]{2}{*}{$\mathbf{P}$} & \multirow[t]{2}{*}{$\chi^{2}$} \\
\hline & $\begin{array}{l}\text { Low } \\
\text { stress }(\leq 1) \\
\text { n }(\%)\end{array}$ & $\begin{array}{l}\text { High } \\
\text { stress(>1) } \\
\text { n }(\%)\end{array}$ & & & \\
\hline \multicolumn{6}{|c|}{ Duration of Employment (Months) } \\
\hline$\leq 24$ & $87(74.4)$ & $30(25.6)$ & $117(37.74)$ & \multirow{4}{*}{0.850} & \multirow{4}{*}{0.799} \\
\hline 25 to 39 & $56(78.9)$ & $15(21.1)$ & $71(22.90)$ & & \\
\hline 40 to 54 & $59(78.7)$ & $16(21.3)$ & $75(24.19)$ & & \\
\hline$\geq 55$ & $37(78.7)$ & $10(21.3)$ & $47(15.16)$ & & \\
\hline \multicolumn{6}{|l|}{ Working Section } \\
\hline Cutting & $16(84.2)$ & $3(15.8)$ & $19(6.13)$ & \multirow[b]{2}{*}{0.069} & \multirow[b]{2}{*}{8.712} \\
\hline Sewing & $147(79.5)$ & $38(20.5)$ & $185(59.68)$ & & \\
\hline
\end{tabular}


DOI: $10.21522 / \mathrm{TIJPH} .2013 .05 .04$. Art056

ISSN: $2520-3134$

\begin{tabular}{|c|c|c|c|c|c|}
\hline Quality control & $25(65.8)$ & $13(34.2)$ & $38(12.26)$ & & \\
\hline Operator & $20(90.9)$ & $2(9.1)$ & $22(7.09)$ & & \\
\hline Finishing & $31(67.4)$ & $15(32.6)$ & $46(14.84)$ & & \\
\hline \multicolumn{6}{|c|}{ Total work time per week (hours) } \\
\hline$\leq 48$ & $12(75.0)$ & $4(25.0)$ & $16(5.16)$ & \multirow{3}{*}{0.455} & \multirow{3}{*}{1.575} \\
\hline $49-54$ & $19(67.9)$ & $9(32.1)$ & $28(9.03)$ & & \\
\hline$>54$ & $208(78.2)$ & $58(21.8)$ & $266(85.81)$ & & \\
\hline
\end{tabular}

\section{Relationship between age, total work time per week and self- reported health problems}

This table 8 shows that the highest percentage of back pain $(68.1 \%)$, neck pain (35.4\%), shoulder pain (38.9\%), breathing problem (23.0\%), chronic cough (14.2\%), pain/burning of eyes (38.9\%), fatigue $(52.2 \%)$ and general weakness $(28.3 \%)$ were found in respondents of 30 years or above. But in case of headache, stomach problem and painful/burning micturation highest percentage found in respondents of 20years or below. In case of sleeplessness highest percentage found in respondents of 21-29 years. Significant association $(\mathrm{p}<0.05)$ between age and back pain, shoulder pain, stomach problem, pain/burning of eyes, fatigue, painful/burning micturation, general weakness were detected. This table shows that the highest percentage of back pain (87.5\%), neck pain (43.8\%), shoulder pain (37.5\%), sleeplessness $(25.0 \%)$ and pain/burning of eyes $(43.8 \%)$ were found in respondents those are working for 48 hours or below per week. Significant association $(\mathrm{p}<0.05)$ between total work time per week and back pain were detected.

Table 8. Relationship between age, total work time per week and self- reported health problems $n=310$

\begin{tabular}{|c|c|c|c|c|c|}
\hline \multirow{3}{*}{ Characteristic } & \multicolumn{3}{|c|}{ Age (years) } & \multirow[t]{3}{*}{$\chi^{2}$} & \multirow{3}{*}{ p-value } \\
\hline & \multirow{2}{*}{\begin{tabular}{|l|}
$\leq 20$ \\
$(\mathrm{~N}=50)$
\end{tabular}} & \multirow{2}{*}{$\begin{array}{l}21 \text { to } 29 \\
(\mathrm{~N}=147) \\
\text { n } \%\end{array}$} & \multirow{2}{*}{$\begin{array}{l}\geq 30 \\
(\mathrm{~N}=113) \\
\mathrm{n} \%\end{array}$} & & \\
\hline & & & & & \\
\hline \multicolumn{6}{|c|}{ Self-Reported Health problems } \\
\hline Back pain & $8(16.0)$ & $47(32)$ & $77(68.1)$ & 51.411 & $0.000 *$ \\
\hline Neck pain & $10(20)$ & $49(33.3)$ & $40(35.4)$ & 4.032 & 0.133 \\
\hline Shoulder pain & $9(18.0)$ & $36(24.5)$ & $44(38.9)$ & 9.857 & $0.007 *$ \\
\hline Headache & $31(62.0)$ & $83(56.5)$ & $51(45.1)$ & 5.138 & 0.077 \\
\hline Breathing problem & $9(18.0)$ & $26(17.7)$ & $26(23.0)$ & 1.251 & 0.535 \\
\hline Stomach problem & $23(46.0)$ & $44(29.9)$ & $16(14.2)$ & 19.346 & $0.000 *$ \\
\hline Chronic cough & 00.0 & $8(5.4)$ & $16(14.2)$ & 11.800 & $0.003 *$ \\
\hline Pain/Burning of eyes & $17(34.0)$ & $34(23.1)$ & $44(38.9)$ & 7.828 & $0.020 *$ \\
\hline Painful/Burning micturation & $14(28.0)$ & $20(13.6)$ & $2(1.8)$ & 24.316 & $0.000 *$ \\
\hline Sleeplessness & $6(12.0)$ & $32(21.8)$ & $23(20.4)$ & 2.304 & 0.316 \\
\hline Fatigue & $6(12.0)$ & $62(42.2)$ & $59(52.2)$ & 23.346 & $0.000 *$ \\
\hline General weakness & $3(6.0)$ & $22(15.0)$ & $32(28.3)$ & 13.686 & $0.001 *$ \\
\hline
\end{tabular}




\begin{tabular}{|c|c|c|c|c|c|}
\hline \multirow[t]{3}{*}{ Characteristic } & \multicolumn{3}{|c|}{ Total work time per week (hours) } & \multirow{3}{*}{$\chi^{2}$} & \multirow{3}{*}{ p-value } \\
\hline & \multirow{2}{*}{$\begin{array}{l}\leq 48(\mathrm{~N}=16) \\
\mathrm{n} \%\end{array}$} & \multirow{2}{*}{\begin{tabular}{|l|}
$\begin{array}{l}49-54 \\
(\mathrm{~N}=28)\end{array}$ \\
$\mathrm{n} \%$ \\
\end{tabular}} & \multirow{2}{*}{\begin{tabular}{|l|}
$>54$ \\
$(\mathrm{~N}=266)$ \\
$\mathrm{n} \%$ \\
\end{tabular}} & & \\
\hline & & & & & \\
\hline \multicolumn{6}{|c|}{ Self-Reported Health problems } \\
\hline Back pain & $14(87.5)$ & $15(53.6)$ & $103(38.7)$ & 16.208 & $0.000 *$ \\
\hline Neck pain & $7(43.8)$ & $9(32.1)$ & $83(31.2)$ & 1.094 & 0.579 \\
\hline Shoulder pain & $6(37.5)$ & $10(35.7)$ & $73(27.4)$ & 1.484 & 0.476 \\
\hline Headache & $5(31.3)$ & $13(46.4)$ & $147(55.3)$ & 4.067 & 0.131 \\
\hline Breathing problem & $2(12.5)$ & $6(21.4)$ & $53(19.9)$ & 0.586 & 0.746 \\
\hline Stomach problem & $4(25.0)$ & $5(17.9)$ & $74(27.8)$ & 1.310 & 0.520 \\
\hline Chronic cough & $1(6.3)$ & $5(17.9)$ & $18(6.8)$ & & $0.097 * * *$ \\
\hline Pain/Burning of eyes & $7(43.8)$ & $11(39.3)$ & $77(28.9)$ & 2.637 & 0.268 \\
\hline Painful/Burning micturation & $2(12.5)$ & $2(7.1)$ & $32(12.0)$ & & $0.856 * *$ \\
\hline Sleeplessness & $4(25.0)$ & $2(7.1)$ & $55(20.7)$ & 3.238 & 0.198 \\
\hline Fatigue & $5(31.3)$ & $17(60.7)$ & $105(39.5)$ & 5.385 & 0.068 \\
\hline General weakness & $1(6.3)$ & $9(32.1)$ & $47(17.7)$ & 5.193 & 0.075 \\
\hline
\end{tabular}

\section{Discussion}

This was a cross sectional study designed and conducted in a ready-made garment factory of Savar in Dhaka city with the objective of assessing work stress and self- reported health problems in female readymade garment workers. An attempt was also taken to identify socio-demographic and work related characteristics could be related to work stress and self-reported health problems. Among 400 workers, 310 were selected by non-probability (purposive) sampling technique. In this study work stress was estimated by ERI-S. The original ERI was developed by Johannes Siegrist and Diego Montano in 2013. The questionnaire used in the current study included sections that elicited information on personal characteristics, family characteristics, work related factors (duration of employment, working section, daily working hours, weekly overtime hours) and health problems.

In this study the age of the workers ranged between 18 to 40 years and their mean age was 27.26 $( \pm 5.93)$ years. Majority of the workers were belongs to $21-29$ years $(47.4 \%)$. About $36.5 \%$ were 30 years or above. This is similar with the study of Mridula \& Khan. Among 100 respondents, they found $7 \%$ were younger than 19 years, $42 \%$ were aged between $19-25$ years, $34 \%$ were $25-30$ years, $15 \%$ were $31-40$ years and 2\% were above 40 years [2]. Most of the workers were married (71.3\%). Which is not similar with the study conducted in Bangladesh. In which they found majority of the female ready-made garment workers were unmarried [12]. Married women employed to be a financial support for her family.

Most $(88.4 \%)$ of the workers were Muslim, $9.0 \%$ were Hindus, $1.3 \%$ were Buddhist and $1.3 \%$ were Christian. Majority of the respondents (55.5\%) went to school for primary education and $24.5 \%$ went to school for secondary/higher education and $20.0 \%$ never went to school, which is similar with the study of Mridula \& Khan, where $72 \%$ were below primary education level and $28 \%$ were below secondary education level [2]. It is not unfair to say that this is the most common educational level among garments workers. The monthly income of the respondents varies from Tk 5,000 to Tk 9,000 and their mean 
DOI: $10.21522 / \mathrm{TIJPH} .2013 .05 .04$. Art056

ISSN: $2520-3134$

income was Tk $7573.55( \pm 961.06)$. Around $51.3 \%$ of the total respondents reported have a monthly income of more than Tk 7500 , while $48.7 \%$ have Tk 7500 or less.

Above study shows that $58.1 \%$ respondent's family members were in 4-6 persons. Minimum 1 and maximum 12 persons were present in each respondent's family. Almost 37.7\% respondents were employed in the factory for 24 months or less. Majority of the respondents belong to sewing section. In this study it was found that $85.8 \%$ respondents engaged in work for more than 54 hours per week.

When the effort-reward ratio was estimated, we found effort- reward ratio varied from 0.42 to 1.40 and the mean ratio was $0.89( \pm 0.17)$. From effort-reward ratio values $>1$ indicate high stress and $\leq 1$ indicate low stress. This was similar with the study of Sperlich using ERI among 3129 German mothers [13]. About one fifth $(22.9 \%)$ of the workers were belong to high stress category whereas $77.1 \%$ belong to low stress category.

Headache was most $(53.2 \%)$ common health problem for last two months among the workers. Moreover a good number of workers face back pain, fatigue, neck pain, pain/burning of eyes, shoulder pain, stomach problem with the percentage of 42.6, 41.0, 31.9, 30.6, 28.7, 26.8 respectively. This is similar with the study of Mridula \& Khan. Among 100 respondents, they found headache was most common health problem among the female workers. They also found that back pain 31\%, asthma $36 \%$ and stomach problem $26 \%$ [2].

Association between socio-demographic characteristics and work stress: High stress was found to be most prevalent (25.2\%) among 21-29 years age group workers. No significant association between work stress and age was detected ( $\mathrm{p}>0.05$ ) (Table no-6). However Health and safety statistics for 2011/12 estimated 1, 35000 female cases of work-related stress based on Labour Force Survey found that the highest rate observed between 35-44 years age for females [14]. In Luxembourg, they found that, the 25-29 years age group perceives stress to be slightly higher than those in other age groups [15]. High stress was most common among non-schooling workers (25.8\%). Furthermore no significant association between work stress and educational status was detected ( $>>0.05)$ (Table no-6). It is similar with the study of Luxembourg, where surveys found that higher the educational level, lower the stress level [15].

No significant association between work stress and monthly income was detected. High stress was found to be most prevalent among those workers having a monthly income of Tk 7500or less (Table no6). It is fair to say that the workers who receive less to survive in this city where rising prices of essential commodities have made the matter worse. Sometimes even this small amount of money cut for absence of work on a particular day. Sometimes they do not get the payment on time. So when they even fail to survive with this amount, they become high stressed workers. High stress was most prevalent among those having a family of 4 to 6 person $(25.0 \%)$. Furthermore no significant association between work stress and family size was detected ( $p>0.05)$ (Table no-6).

Association between works related characteristics and work stress: High stress was most prevalent (25.6\%) among those workers who are working for 24 months or less. Furthermore no significant association between work stress and duration of employment was detected ( $p>0.05)$ (Table no-7). High stress was most common (34.2\%) among those workers who are working at quality control section. Also no significant association between work stress and working section was detected $(\mathrm{p}>0.05)$ (Table no-7). It was found that high stress was most prevalent (32.1\%) among those workers who are working for 4954 hours per week. Furthermore no significant association between work stress and total work time per week was detected ( $\mathrm{p}>0.05)$ (Table no-7).

Association between socio-demographic characteristics and self-reported health problems: The highest percentage of back pain (68.1\%), neck pain (35.4\%), shoulder pain (38.9\%), breathing problem (23.0\%), Chronic cough (14.2\%), pain/burning of eyes (38.9\%), fatigue $(52.2 \%)$ and general weakness (28.3\%) were found in respondents of 30 years or above. But in case of headache, stomach problem and painful/burning micturation highest percentage found in respondents of 20 years or below. In case of sleeplessness highest percentage found in respondents of 21-29 years. Significant association $(\mathrm{p}<0.05)$ between age and back pain, shoulder pain, stomach problem, pain/burning of eyes, fatigue, 
painful/burning micturation, general weakness were found (Table no-8). This is similar with the study of Akhter. They found significant association between age categories and health problems. They also found headache was most frequent among 16-20 years age group workers [16].

Association between work characteristics and self-reported health problems: This study revealed that highest percentage of back pain (87.5\%), neck pain (43.8\%), shoulder pain (37.5\%), sleeplessness $(25.0 \%)$ and pain/burning of eyes $(43.8 \%)$ were found in respondents those are working for 48 hours or below per week. Significant association $(\mathrm{p}<0.05)$ between total work time per week and back pain were found (Table no-8). Overall findings of this study revealed that one-fifth of the female ready-made garment workers had high stress and headache was most common health problem among them. Work related factors like duration of employment and total work time per week have been found to have significant effect on self-reported health problems.

\section{Conclusion}

A cross sectional study was carried out to asses work stress and self-reported health problems in female ready-made garment workers. From the analysis of the results of the present study, the following conclusion may be drawn: A little over one fifth of female ready-made garment workers had high stress. Headache, back pain, fatigue, neck pain, shoulder pain and stomach problem were the common health problems among the workers. Self-reported health problems were found to be associated with sociodemographic and work related factors. Neither socio-demographic nor work related factors were found to be associated with work stress.

\section{Acknowledgement}

All praises to Almighty Allah for enabling me to complete this thesis in time. I am grateful to faculty members and Thesis Protocol Approval Committee of National Institute of Preventive and Social Medicine (NIPSOM) for providing me the unique opportunity to conduct this thesis for the fulfillment of the Degree of MPH (OEH). I am extremely grateful to my respected teacher Dr. Manzurul Haque Khan, $\mathrm{PhD}$ my supervisor for his continuous support and scholarly guidance despite his busy schedules. Without his valuable advices, constructive suggestions, passion and whole-hearted cooperation, I could never have completed it in time.

\section{References}

[1]. Akhter, S, Salahuddin, AFM, Iqbal, M, Malek, ABMA \& Jahan, N 2010, 'Health and occupational safety for female workforce of garment industries in Bangladesh, Shahjalal University of Science \& Technology, vol. 41, no. 1, pp 1-6.

[2]. Ahamed F. could monitoring and surveillance be useful to establish social compliance in the ready-made garment (RMG) industry of Bangladesh. International Journal of Management and Business Studies. 2013; 3(3):88100.

[3]. Blaug, R, Kenyon, A \& Lekhi, R 2007, 'Stress at work, Research report', The Work Foundation, London, pp. 1-94.

[4]. Buckley, P 2013, 'Stress and Psychological Disorders in Great Britain', Health and Safety Executive, vol. 1, pp. 1-7.

[5]. European Foundation for the Improvement of Living and Working Conditions 2010, 'Work-related stress', Wyattville Road, Loughlinstown, Dublin, Ireland, pp. 1-51.

[6]. Kutalek, R \& Prinz, A 2010, 'Stress and Modern Work: Ethnographic Perspectives from Industries in Bangladesh', Department of General Practice, Centre for Public Health, Medical University of Vienna, Austria, vol. 13, pp. 24-33.

[7]. Mridula, S, M \& Khan, K, A 2009, 'Working Conditions and Reproductive Health Status of Female Garments Workers of Bangladesh', Bangladesh Occupational Safety, Health and Environment Foundation (OSHE), pp. 5-18.

[8]. Nahar, N, Ali, R \& Begum, F 2010, 'Occupational health hazards in garment sector, Bangladesh Agricultural University, Mymensingh, vol. 1, pp. 1-6. 
DOI: $10.21522 / \mathrm{TIJPH} .2013 .05 .04$. Art056

ISSN: $2520-3134$

[9]. Park, J 2007, 'Work stress and job performance'. Labour and Household Surveys Analysis Divisio, Statistics Canada, Catalogue no. 75-001-XIE, pp. 1-13.

[10]. Rahman, A, Ahmed, A \& Noushin, L 2013, 'Labor Law Practices in EPZ Area: An Impact of RMG Sector in Bangladesh', United International University (UIU), Dhaka, Vol. 3, pp.1

[11]. Susan, L \& Joseph 2001, 'Workers perceptions of how jobs affect health: a social ecological perspective'. University of California, Los Angeles. Vol. 6, no. 2, pp. 101-113.Sperlich, S, Peter, R, Geyer, S 2012, 'Applying the effort-reward imbalance model to household and family work: a population-based study of German mothers', $B M C$ Public Health, pp. 1-12.

[12]. Siegrist, J, Starkea, D, Chandolab, T, Godinc, I, Marmotb, M, Niedhammerd, I \& Petere, R 2004, 'The measurement of effort-reward imbalance at work: European comparisons, department of medical sociology, University of Duesseldorf, pp. 1483-1499.

[13]. Siegrist, J, Li, J \& Montano, D 2014, 'ERI-Questionnaires user guide', University of Duesseldrof, Germany, pp 1-28.

[14]. Steinisch, M, Yusuf, R, Jian, L, Rahman, O, Hasan, M, Strümpell, C \& Fischer, J 2013, 'Work stress: Its components and its association with self-reported health outcomes in a garment factory in Bangladesh-Findings from a cross-sectional study', Mannheim Institute of Public Health, Heidelberg University, Health \&Place. Vol.4, pp. 123-130.

[15]. Tennant, C 2001, 'Work-related stress and depressive disorders', Department of Psychological Medicine, University of Sydney and Royal North Shore Hospital, Australia, Journal of Psychosomatic Research, pp. 1-8.

[16]. WHO 2010, 'Health Impact of Psychosocial Hazards at Work: An Overview', Institute of Work, Health \& Organizations, University of Nottingham, pp. 1-126. 